\title{
Experimental investigation of solar cooker with dual sensible heat storage unit for evening cooking
}

\author{
Avadhesh Yadav
}

\begin{abstract}
In this article, the thermal performance of dual sensible heat storage unit in a solar cooker based on parabolic dish collector for evening cooking is experimentally investigated. In the experimental setup, solar cooker with dual sensible heat storage unit was placed on absorbing plate of parabolic dish collector. During sunshine hours, the dual sensible heat storage unit stores solar heat and in the evening time, firstly the solar cooker with sensible heat storage unit is transferred to an insulator box and then loaded with cooking food. Inner sensible heat storage material transfers its stored heat to the cooking pot while the outer sensible heat storage material helps in compensating the heat loss during the transfer of solar cooker from absorber plate to insulator. It has been found that, food was cooked when transfer time is 05 minutes, partially cooked when transfer time is $\mathbf{1 0}$ minutes and not cooked when transfer time is $\mathbf{1 5}$ minutes.
\end{abstract}

Keywords- Thermal performance, parabolic dish collector, solar cooker, sensible heat storage unit.

\section{Introduction}

Solar cooking is better substitute for cooking by fuel or wood in India. Solar energy has become one of the most promising alternative energy resources because it is free, environmental friendly and available in abundance. From the last few decades, solar energy is utilized in the field of cooking using different types of collector such as box type solar cooker, parabolic dish collector, parabolic trough collector and evacuated tube collector. Several efforts were made for day and evening cooking using solar cooker with thermal storage.

Department of Mechanical Engineering, National Institute of Technology, Kurukshetra Haryana-136119, India

Tel. +91-9896103634
Sharma et al. [1] designed and developed a cylindrical PCM storage unit for a solar cooker with two reflectors and compared the performance of that solar cooker with a standard solar cooker. Acetamide was used as PCM and experimental results showed that the melting temperature of PCM should be in the range of $105^{\circ} \mathrm{C}$ to $110^{\circ} \mathrm{C}$ for evening cooking. Schwarzer and Silva [2] tested a solar cooking system with or without heat storage in different countries of the world. The system presented many interesting features such as possibility of indoor and night cooking, heat flow control in the pots, modularity and the possibility of further adjustments to incorporate a baking oven. Sharma et al. [3] investigated the thermal performance of a prototype solar cooker based on an evacuated tube collector with PCM storage unit. The system achieved high temperatures up to $130^{\circ} \mathrm{C}$ without tracking when erythritol was used as a PCM, which was sufficient to cook food during late evening. Chaudhary et al. [4] investigated a solar cooker based on parabolic dish collector with phase change material. It was observed that solar cooker with phase change material having outer surface painted black along with glazing stores $32.3 \%$ more heat as compared to PCM in ordinary solar cooker. Lecuona et al. [5] simulated a parabolic type solar cooker by using finite difference method. A numerical model was used to study its transient behavior with two different types of PCMs: Paraffin and Erythritol. Erythritol is an advantage for fast cooking due to high melting temperature and conductivity. Farooqui Suhail [6] presented a solar cooker based on fresnel lens type collector. The maximum temperature attained in the experiment was $250^{\circ} \mathrm{C}$. Heat absorption capacity of that collector was five times more than conventional box type solar cooker. Saini et al. [7] experimentally investigated the thermal performance of a solar cooker with acteamide as PCM based on parabolic trough 
Proc. of the Intl. Conf. on Advances in Civil, Structural and Mechanical Engineering - ACSM 2015.

Copyright $(\odot$ Institute of Research Engineers and Doctors, USA .All rights reserved.

ISBN: 978-1-63248-039-2 doi: 10.15224/ 978-1-63248-039-2-25

collector with vacuum tube receiver. It was observed the rate of evening cooking was found to be approximately 1.63 to 4.44 times faster as compared to noon cooking.

Many researchers have worked on solar cooker based on box type collector, evacuated tube solar collector, parabolic dish collector and parabolic trough collector with phase change thermal storage unit but none of them worked on solar cooker based on parabolic dish collector with dual thermal storage unit. The objective of this paper is to investigate the thermal performance of the solar cooker is studied under different transfer time of cooker from the dish to insulator box. The experimental setup is installed at NIT Kurukshetra, India $\left[29^{\circ} 58^{\prime}\right.$ (latitude) North and $76^{\circ} 53^{\prime}$ (longitude) East].

\section{Experimental setup}

This experiment is performed to investigate the thermal performance of solar cooker with the stone pebbles and sand in inner and outer space respectively. The test section of solar cooker is based on parabolic dish collector. This system consists of parabolic dish collector and solar cooker as shown in figure 1. The experimental setup consists of following components:

A. Parabolic solar dish collector

$B$. Solar cooker with sensible heat storage unit

$C$. Insulator box

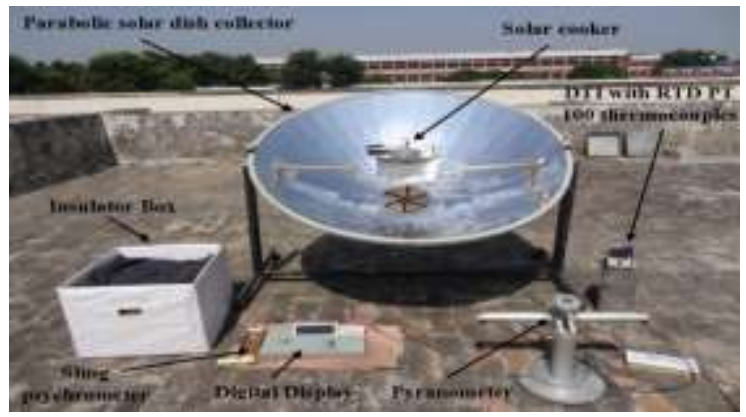

Figure 1: Photograph of the experimental setup

\section{A. Parabolic solar dish collector}

The solar dish is a point focusing collector which includes concentrator, absorbing plate for placing the cooker and frame as shown in figure.2. At the focal length of parabolic dish collector, an absorbing plate is provided upon which cooker is to be placed. The tracking of parabolic dish collector is manually.
Specifications of the parabolic dish collector are shown in Table 1.

TABLE 1: SPECIFICATIONS OF DISH COLLECTOR

\begin{tabular}{|l|c|}
\hline Diameter of outer ring & $1.4 \mathrm{~m}$ \\
\hline Focal length of dish & $0.2 \mathrm{~m}$ \\
\hline Dish rim angle & $120.5^{\circ}$ \\
\hline Aperture area of dish & $1.539 \mathrm{~m}^{2}$ \\
\hline Concentration ratio of dish & 33 \\
\hline
\end{tabular}

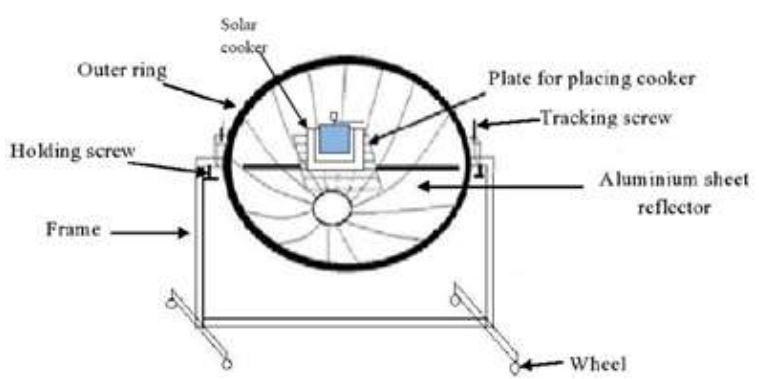

Figure 2: Schematic diagram of parabolic solar dish collector

\section{B. Solar cooker with Sensible heat storage materials}

Solar cooker is made up of two hollow concentric cylindrical pots of aluminum and a pressure cooker placed at their centre. The diameter of inner and outer pots is $0.23 \mathrm{~m}$ and $0.285 \mathrm{~m}$ respectively while the pressure cooker has diameter $0.13 \mathrm{~m}$ and height as $0.11 \mathrm{~m}$. The inner space of cooker is filled with stone pebbles and the outer space with sand. The section view and photo of solar cooker are shown in figure 3 (a) and 3(b) respectively.

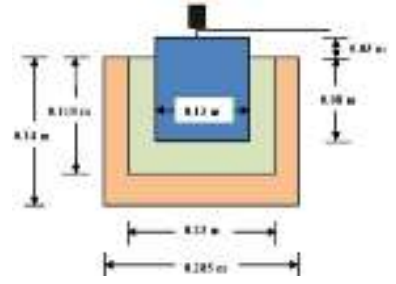

(a)

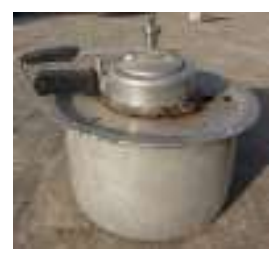

(b)
Figure 3: (a) Section view of solar cooker (b) photograph of solar cooker

\section{Insulator box}

A cardboard box filled with wooden chips having dimension as $0.534 \mathrm{~m} \times 0.534 \mathrm{~m} \times 0.406 \mathrm{~m}$ respectively is used as an insulator, as shown in figure 4. A cylendrical space having diameter $0.30 \mathrm{~m}$ and length $0.15 \mathrm{~m}$ is created at its centre for placing the solar cooker. Top insulation is provided by using a sack which filled with wooden chips. 


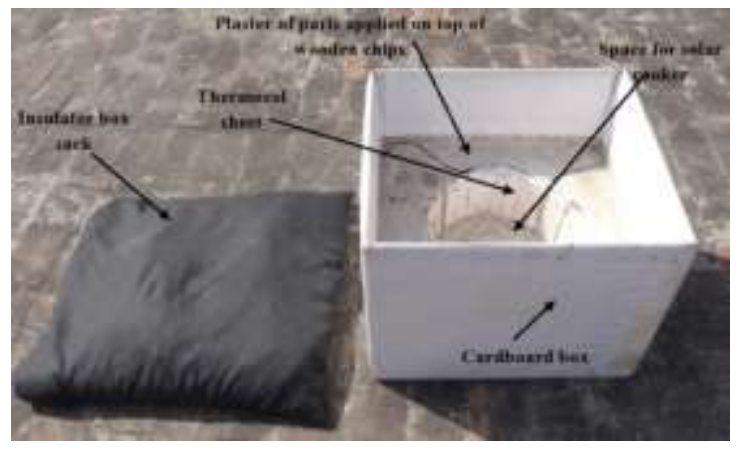

Figure 4: Photograph of insulator box with sack

\section{Measuring Devices and Instruments}

Sensible heat storage materials and cooking medium temperature are measured with RTD PT100 thermocouples which are connected with a digital temperature indicator that shows the temperature with a resolution of $0.1^{\circ} \mathrm{C}$.

Dry bulb temperature of ambient air is measured with sling psychrometer.

The solar radiation intensity is measured during the day time with a Pyranometer.

\section{Iv. System Operation}

The main objective of this experimental setup is to investigate the thermal performance of dual sensible heat storage unit in solar cooker for successful evening cooking. In the experimental setup, stone pebbles are filled in the inner space while sand in the outer space of the solar cooker. Solar cooker is placed on the absorbing plate of dish collector and the system is exposed to solar radiation from 13:00 hr to 16:00 hr. Solar radiations are made to concentrate on the solar cooker by the parabolic dish collector. The available heat is absorbed by dual sensible heat storage unit. The dish collector is tracked manually in every 15 minutes with the movement of sun. At 16:00 $\mathrm{hr}$, the solar cooker is lifted from the dish collector and placed in the insulator box and loaded with $200 \mathrm{~g}$ rice and $400 \mathrm{ml}$ water for evening cooking. During evening cooking, inner material transfer its stored heat to the cooking pot while the outer material helps in compensating the loss to maintain its performance even during the transfer of cooker from the dish to insulator box.

\section{v. Analysis of Experimental Data}

Heat stored by the sensible heat storage material is given as

$$
\mathrm{Q}_{\mathrm{m}}=\mathrm{m}_{\mathrm{m}} \mathrm{C}_{\mathrm{m}}\left(\mathrm{T}_{\mathrm{m}}-\mathrm{T}_{\mathrm{a}}\right)
$$

\section{vI. Experimental Results and Discussion}

In the experimental setup, cooking was conducted at evening time using a solar cooker with dual sensible heat storage unit based on parabolic dish type collector. The performance of the solar cooker is studied under different transfer time of cooker from the dish to insulator box. The experiments were conducted during the month of September 2014. Every day, solar collector was exposed to solar radiation at 12:50 hr and readings were taken from 13:00 hr up to $20: 00 \mathrm{hr}$ at an every interval of 30 minutes.

(a) Solar cooker for transfer time of 05 minutes; September 16, 014

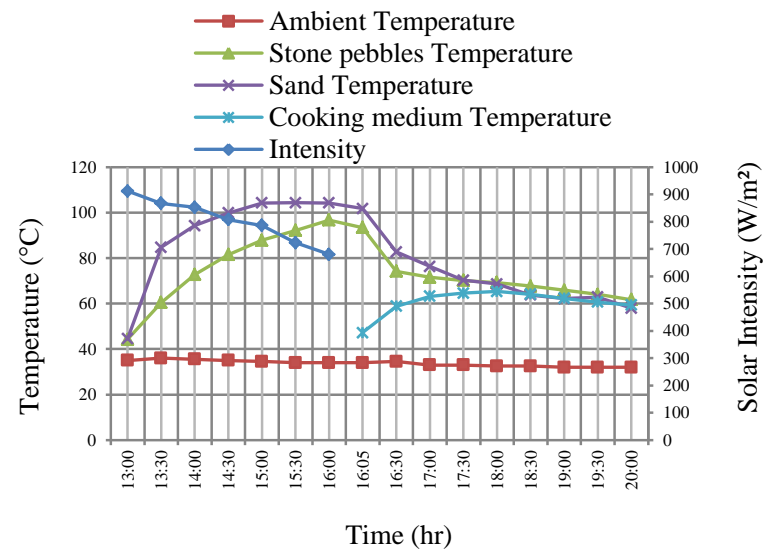

Figure 5: Variation of temperature and solar radiation intensity for transfer time of 05 minutes; September 16, 2014

On September 16, During the day, the maximum intensity was $912 \mathrm{~W} / \mathrm{m}^{2}$ at 13:00 $\mathrm{hr}$ and the ambient temperature was in the range of $32^{\circ} \mathrm{C}$ to $36^{\circ} \mathrm{C}$. The maximum temperatures of sand and stone pebbles were $104.3^{\circ} \mathrm{C}$ and $96.7^{\circ} \mathrm{C}$ respectively. The figure 5 shows that the sand and stone pebbles were charged continuously till 16:00 $\mathrm{hr}$ and afterwards it started discharging the stored energy. The maximum temperature of food in cooking pot reached $65.3^{\circ} \mathrm{C}$ at 18:00 $\mathrm{hr}$ and it was observed that at 20:00 hr the food temperature was $59.3^{\circ} \mathrm{C}$. The food was found to be cooked. 
Proc. of the Intl. Conf. on Advances in Civil, Structural and Mechanical Engineering - ACSM 2015.

Copyright ( $\odot$ Institute of Research Engineers and Doctors, USA .All rights reserved.

ISBN: 978-1-63248-039-2 doi: 10.15224/ 978-1-63248-039-2-25

(b) Solar cooker for transfer time of 10 minutes; September 22, 2014

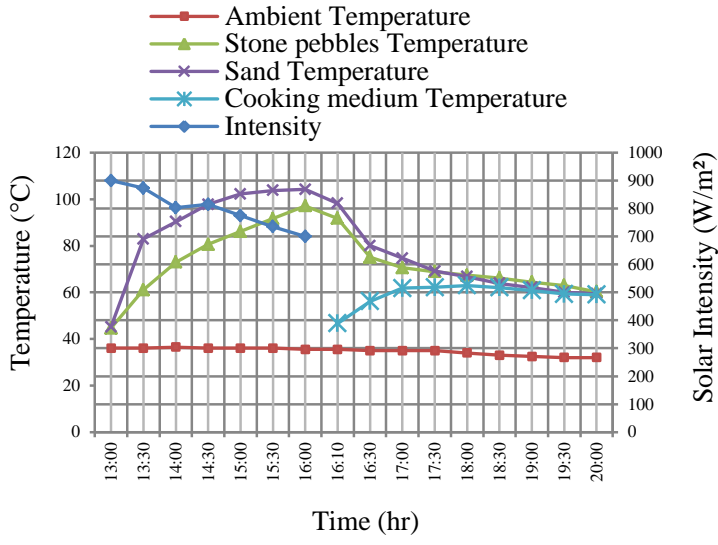

Figure 6: Variation of temperature and solar radiation intensity for transfer time of 10 minutes; September 22, 2014

On September 22, Sand temperature and stone pebbles temperature rises reaching to their maximum values of $104.2^{\circ} \mathrm{C}$ and $97.2^{\circ} \mathrm{C}$ as shown in figure 6 . Maximum solar intensity was $900 \mathrm{~W} / \mathrm{m}^{2}$ at $13: 00 \mathrm{hr}$ and the ambient temperature lies in the range of $32^{\circ} \mathrm{C}$ to $36^{\circ} \mathrm{C}$. The maximum temperature of food was found to be $63^{\circ} \mathrm{C}$ at 18:00 hr. At 20:00 hr the temperature of food was found to be $59^{\circ} \mathrm{C}$ and the food was partially cooked.

(c) Solar cooker for transfer time of 15 minutes; September 23, 2014

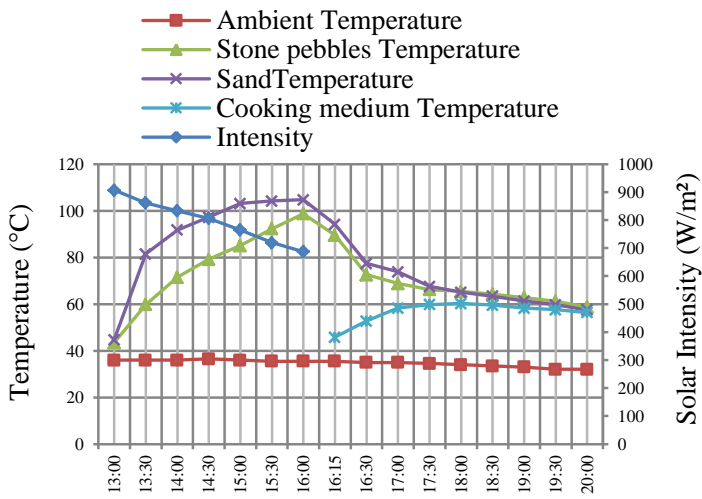

Time (hr)

Figure 7: Variation of temperature and solar radiation intensity for transfer time of 15 minutes; September 23, 2014

On September 23, the maximum solar intensity was $907 \mathrm{~W} / \mathrm{m}^{2}$ at 13:00 $\mathrm{hr}$. The maximum temperature attained by sand and stone pebbles was $104.7^{\circ} \mathrm{C}$ and $98.7^{\circ} \mathrm{C}$ respectively, as shown in figure 7 . The maximum temperature of $60.2^{\circ} \mathrm{C}$ was attained by food at 18:00 hr. At 20:00 hr the temperature of food was found to be $56.4^{\circ} \mathrm{C}$ and the food was not cooked.

(d) Heat stored by sensible heat storage materials for different cases

In different cases of the experiment performed, the energy stored by sensible heat storage materials during charging process is shown in the figure 8 .

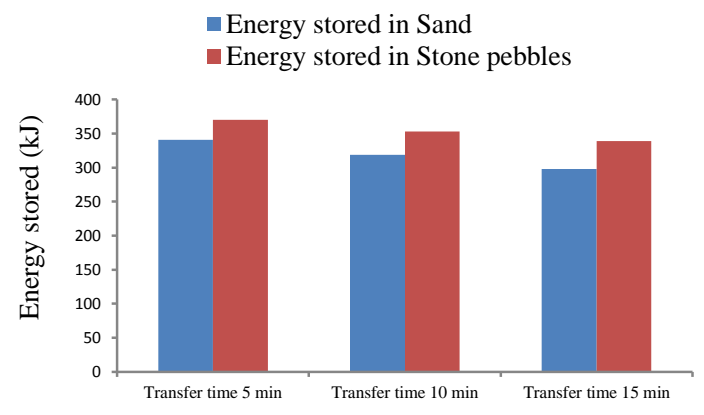

Figure 8: Heat stored by sensible heat storage materials

\section{vII. Conclusions}

1. During the transfer process, when the transfer time is 5 minutes, 10 minutes and 15 minutes then the temperature of outer sensible heat storage unit drops to $3^{\circ} \mathrm{C}, 6^{\circ} \mathrm{C}$ and $10^{\circ} \mathrm{C}$ respectively.

2. The maximum energy stored by stone pebbles during the transfer of 05 minutes, 10 minutes and 15 minutes is found as $370 \mathrm{~kJ}$, $353 \mathrm{~kJ}$ and $339 \mathrm{~kJ}$ respectively, where as for sand it is $341 \mathrm{~kJ}, 319 \mathrm{~kJ}$ and $259 \mathrm{~kJ}$ respectively.

3. Food was cooked when transfer time is 05 minutes, partially cooked when transfer time is 10 minutes and not cooked when transfer time is 15 minutes.

\section{Nomenclature}

$\mathrm{Q}_{\mathrm{m}} \quad$ heat stored by material, $\mathrm{kJ}$

$\mathrm{m}_{\mathrm{m}} \quad$ mass of material, $\mathrm{kg}$

$\mathrm{C}_{\mathrm{m}} \quad$ specific heat of material, $\mathrm{kJ} / \mathrm{kg}^{\circ} \mathrm{C}$

$\mathrm{T}_{\mathrm{m}} \quad$ temperature of material, ${ }^{\circ} \mathrm{C}$

$\mathrm{T}_{\mathrm{a}} \quad$ ambient temperature, ${ }^{\circ} \mathrm{C}$ 
Proc. of the Intl. Conf. on Advances in Civil, Structural and Mechanical Engineering - ACSM 2015.

Copyright $($ Institute of Research Engineers and Doctors, USA .All rights reserved.

ISBN: 978-1-63248-039-2 doi: 10.15224/ 978-1-63248-039-2-25

\section{References}

[1]. Sharma S.D., Buddhi D., Sawhney R.L., Sharma A., 2000, "Design, development and performance evaluation of a latent heat storage unit for evening cooking in a Solar cooker", Energy Conversion and Management, vol. 41, pp 1497-1508.

[2]. Schwarzer K. and Silva M.E.V., 2003, "Solar cooking system with or without heat storage for families and institutions", Solar Energy, vol. 75, pp 35-41.

[3]. Sharma S.D., Iwata T., Kitano H., Sagara K., 2005, "Thermal performance of a Solar cooker based on an Evacuated tube collector with a PCM storage unit", Solar Energy, vol. 78, pp 416-426.

[4]. Choudhary A., Kumar A., Yadav A., 2013, "Experimental investigation of solar cooker based on parabolic dish collector with phase change thermal storage unit in Indian climatic conditions", Renewable \& Sustainable Energy, vol.5 023107.

[5]. Lecuona A., Nogueira J.I., Ventas R., Hidalgo M.D.C.R., Legrand M., 2013, "Solar cooker of the portable Parabolic type incorporating heat storage based on PCM", Applied Energy, vol.111, pp 1136-1146.

[6]. Farooqui S.Z., 2013, "A vacuum tube based improved solar cooker", Sustainable Energy technologies and Assessments, vol.3, pp 33-39.

[7]. Saini K., Gagandeep, Singh H. and Yadav A., 2014, "Solar cooker with PCM unit based on parabolic trough collector with vacuum tube receiver: Experimental investigation", Encyclopedia of Energy Engineering and Technology, Article in Press. 